\title{
UNDERSTANDING THE DEMAND DRIVEN MATERIAL REQUiREMENTS PlanNing SCOPE OF APPLICATION: a Critical Literature ReVieW
}

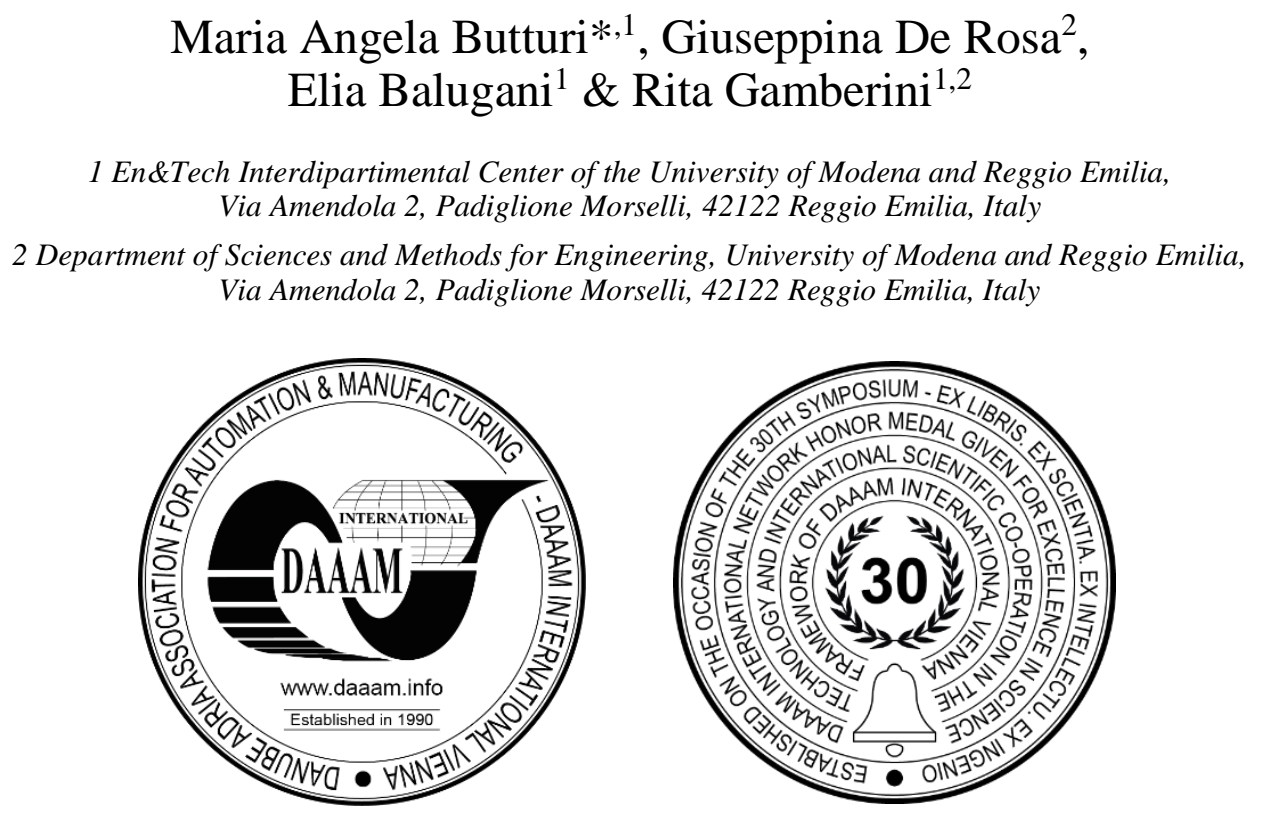

This Publication has to be referred as: Butturi, M[aria] A[ngela]; De Rosa, G[iuseppina]; Balugani, E[lia] \& Gamberini, R[ita] (2021). Understanding the Demand Driven Material Requirements Planning Scope of Application: a Critical Literature Review, Proceedings of the 32nd DAAAM International Symposium, pp.0462-0471, B. Katalinic (Ed.), Published by DAAAM International, ISBN 978-3-902734-33-4, ISSN 1726-9679, Vienna, Austria DOI: $10.2507 / 32$ nd.daaam.proceedings.067

\begin{abstract}
The supply chains complexity generated by the dynamic market demand imposes the improvement of the classical production control systems. A recently introduced method, the Demand Driven Material Requirements Planning (DDMRP), is proposed as an upgrade of the Material Requirements Planning (MRP), widely used in industry, capable of overcoming the nervousness of MRP environment and the bullwhip effect affecting supply chains under uncertainties. The DDMRP approach, however, is still not well established since the conditions for its application are still little investigated. Thus, this study aims at reviewing the existing scientific literature concerning DDMRP method in order to critically analyse its main scope of application as well as its real practical performance. From the reviewed literature three main research lines emerged: DDMRP basic principles, comparison with other methodologies, and case studies. The analysis of both research oriented papers and case studies points out some critical issues that are limiting the diffusion of the DDMRP method, including the additional costs necessary to adapt the in use control and planning software. The main criticality of the method is recognized to be the high subjectivity affecting the positioning of the buffers, and the need for classifying the suitable sectors of application.
\end{abstract}

Keywords: Production control systems; Demand and lead time uncertainties; Demand Driven Material Requirements Planning; Inventory level; Supply Chain complexity.

\section{Introduction}

The current evolution of the market, guided by the increasingly volatile needs of the customers, put companies in front of new challenges: the supply chain has become more complex, moving from mainly linear and vertically integrated structures to highly branched ones; greater volumes of material are requested and handled; the heterogeneity and 
complexity of the available products have significantly increased; technological advancement has contributed to rapidly changing consumer preferences, reducing the life cycles of products and making them more and more customizable. In the context of production planning, these issues translate into the need for improving the "classical" production control systems (PCS) to adjust them to the new market requirements. Many PCS's emerged in the last couple of decades to respond to the market evolution as well as to specific environments of application [1].

One of the most widely used production control and planning systems in the industry is MRP (Material Requirements Planning), and this system is often embodied in the enterprise resource planning (ERP) software [2]. MRP techniques use the bill of materials (BOM), the master production schedule (MPS), and the inventory records to schedule the required materials replenishment for the manufacturing of the final product for a given time horizon. It is based on a control system for the planning of stocks and production of the push-type, according to which organizations use forecasts to determine the market demand for their products. The MRP approach works well in a deterministic context, while it shows some weaknesses under uncertainties concerning the demand and lead time [3]. The continual adjustments in the scheduling due to even small changes of the codes of the higher levels of the BOM make the MRP unstable, causing the so-called MRP nervousness [4]. Moreover, the dependence between the nodes of the supply chain produces the bullwhip effect, transmitting and amplifying the variability that affects all the levels of the BOM to all the nodes in the supply chain [5].

Among the new approaches proposed to overcome MRP criticalities [6], [7], [8], the Demand Driven MRP (DDMRP) was firstly introduced in 2011 by Ptak and Smith [9], as a new PCS. According to the authors [10], the DDMRP is a hybrid push-pull method that combines some of the principles and practices of MRP, Lean, Six Sigma, and the Theory of Constraints, resolving possible conflicts among the different methods through innovative solutions. It uses Lean Manufacturing principles to allow a pull logic with approximation to real demand and the concept of signalling mechanisms to have visibility of stock levels; like TOC it focuses on products that limit the system performance and uses buffers to protect the process; from Six Sigma it considers the strong sensitivity to variations, trying to control them. DDMRP considers a decoupled lead time, keeping some pre-defined BOM components in stock, and uses the Available Stock Equation (ASE) to calculate, daily, the future stock based on actual demand and orders in production. The methodology is implemented through five steps: the strategic inventory positioning, where the positioning of the buffers responds to the need of decoupling the planning and execution horizons of the logistics chain reducing the bullwhip effect; the definition of the buffers profiles and levels, for sizing the three buffer layers (red, yellow and green) calculated by three factors: item type, lead time and variability; the dynamic adjustments of the buffers' layers with changes in demand; the demand-driven planning, for creating the production and purchase orders; the execution phase, to manage the orders once they are generated. For a more detailed analysis of the method see for example [11], [12].

In the last years the DDMRP method, initially developed by practitioners, gained new interest within the academic research that produced both theoretical and empirical studies [1]. However, though the method presents some innovative aspects, mainly regarding its ability in overcoming the bullwhip effect typical of supply chains and the MRP nervousness, the conditions for its application and its real practical performance are still little investigated. Only a few literature reviews tried to organise the available studies and analyse some specific issues related to DDMRP implementation. Thus, this study aims at reviewing the existing scientific literature concerning the DDMRP method, in order to investigate the more recent results on the methodology applicability and effectiveness in the industrial environment. It is organised as a critical literature review that updates the few available reviews, providing additional insights. Following the three main research lines that emerged from the literature, the paper discusses the advantages and limits of the methodology in the view of the various authors, analyses the critical issues that can limit its application, and outlines its possible future developments.

\section{Literature review methodology}

\subsection{Scope of the review}

Despite the recent attention to the study and application of the DDMRP and the number of articles available on the website of the Demand Driven Institute (DDI), the consulting company founded by Ptak and Smith operating in the DDMRP field, the method is still under-investigated by the scholars. Therefore, this literature review aims at exploring the academic perspective on the methodology and is driven by three main research questions:

1. Are the basic principles of DDMRP improved by academic research?

2. What are its required future evolutions according to the scientific community view?

3. Considering the benefits and difficulties encountered by the manufacturing industry applying the DDMRP, in what productive environments did this system prove useful?

Our study aims at updating and extending the three literature reviews published on the DDMRP methodology, which reveal different focuses. Marzougui et al. identify papers containing simulated or real case studies with the aim of comparing the academic results with the improvements achieved by companies implementing the DDMRP method as claimed by the DDI; master's theses and non-English paper are excluded from the review, which is updated to 2019 [11]. The systematic literature review of Orue et al. analyses the studies investigating the standardization of the procedure to implement the DDMRP model, to build up a standard application model enabling full exploitation of the methodology potential benefits, through reducing the implementation time and costs, the possible errors, and improving the quality of the process; also this review is updated to 2019 [13]. 
The more recent systematic review, presented by Azzamouri et al. and updated to April 2020, explores the literature contributions to three main issues providing knowledge on the method: the method validation, the improvement of the original techniques, and the proposal of new tools for its implementation [14].

\subsection{Publications search and selection}

The exploration of the literature was conducted using the online databases Science Direct, Web of Science and Google Scholar and completed on May 14, 2021. An initial set of papers was identified employing the keywords "Demand Driven Material Requirements Planning", "DDMRP", and "Demand Driven"; the saturation point occurred when the same articles kept appearing in search engines. Due to the relatively small number of collected papers and to ensure that our research was as comprehensive as possible, we further conducted a snowball search. At the end of the search process, we collected a total of 140 papers.

Then, we proceeded with the selection of the relevant papers according to the following exclusion criteria:

- Duplicates between search engines have been removed, i.e. 48 papers.

- Both qualitative and quantitative articles were selected, considering publications in academic journals or conferences, and Master and $\mathrm{PhD}$ degree theses; in this review, we included the theses because they made available the knowledge on the DDMRP methodology to the wide practitioners' community in their different national languages. Some magazines and newspapers articles written by consultants specialized in Supply Chain and logistics, mainly available on the DDI website, have been excluded since their main purpose could be marketing their product to companies and this could change the way of presenting the method, i.e. 33 papers.

- The publications without the specified keywords within the article were excluded, finding that they dealt with topics not directly related to the DDMRP (e.g. Decoupled lead time), i.e. 4 papers.

- The publications without an exclusive focus on the DDMRP methodology applied to the planning of material requirements in the supply chain (e.g. articles dealing with the broader Demand Driven Enterprise Model) were excluded, i.e. 7 papers.

- Since the scope of this review is to analyse the DDMRP related concepts that emerged in the literature in recent years, we defined as review temporal boundaries the period 2016-2021; in fact, starting from 2016 there is an increase in the number of scientific publications (Figure 1), following a few years the first introduction of the DDMRP methodology in 2011 [9]. Other 9 papers were thus excluded.

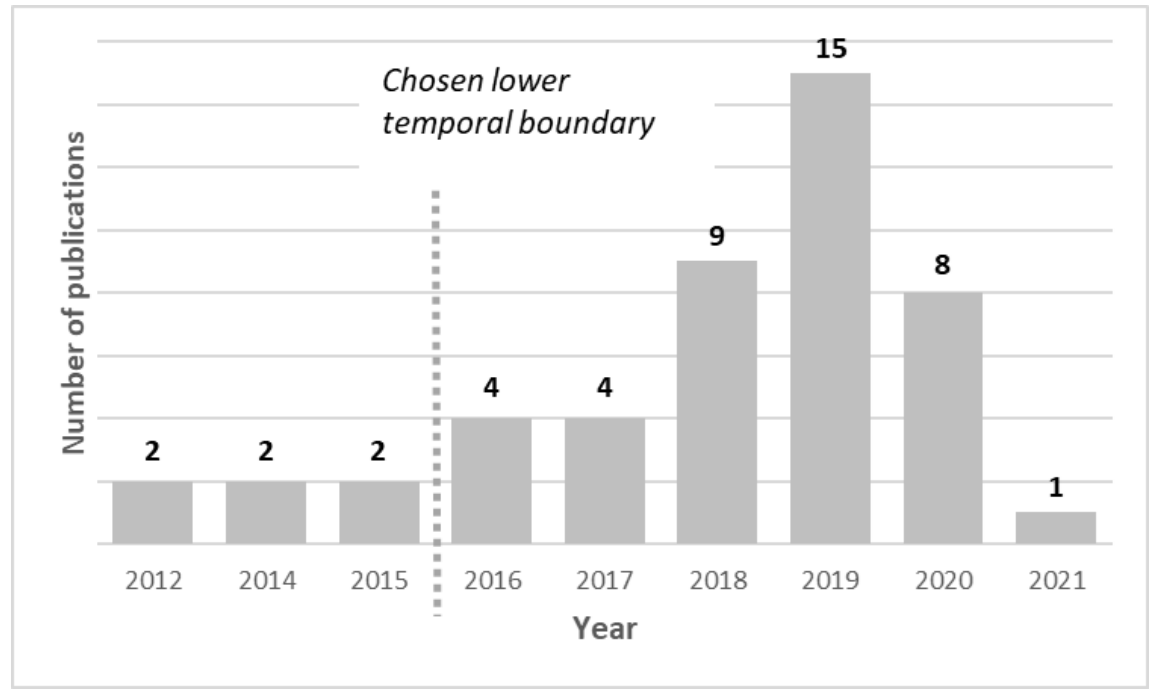

Fig. 1. Temporal distribution of the selected DDMRP publications.

Finally, a total of 39 relevant publications were selected for further analyses: 12 scientific articles, 6 conference papers, and 21 theses.

\section{Results and discussion}

\subsection{Papers classification}

To answer the research questions, the selected publications were classified analysing their content according to three main categories revealed by the review: DDMRP basic principles, comparison with other methodologies, and case studies (Table 1). 


\begin{tabular}{|l|l|l|}
\hline Content category & REF. & $\begin{array}{l}\text { N. of } \\
\text { studies }\end{array}$ \\
\hline $\begin{array}{l}\text { DDMRP basic } \\
\text { principles }\end{array}$ & $\begin{array}{l}\text { [15] [16] [17] [18] [19] [20] [21] [22] [23] [24] } \\
\text { [25] [26] [27] }\end{array}$ & 13 \\
\hline $\begin{array}{l}\text { Comparison with } \\
\text { other methodologies }\end{array}$ & [28] [29] [30] [12] [31] [32] [33] [34] & 8 \\
\hline Case studies & $\begin{array}{l}\text { [35] [36] [37] [38] [39] [40] [41] [42] [43] [44] } \\
\text { [45] [30] [46] [47] [48] [49] [50] }\end{array}$ & 17 \\
\hline
\end{tabular}

Table 1. Classification of the selected studies according to the identified categories.

Table 1 shows that the research papers (including both the DDMRP basic principles and comparison with other methodologies categories) are more than the case studies, confirming that although some companies are now implementing DDMRP, still very few of them share their data and collaborate to scientifically study the advantages or critical issues related to the method within their specific environment [14]. The content of the papers is then analysed and discussed in relation to the three identified categories.

\subsection{Group 1: DDMRP basic principles}

The first group of publications includes 13 items, of which 7 articles were published in scientific journals or conferences and 6 Master degree theses. These publications mainly aim at examining the principles and basic concepts of the DDMRP methodology, showing future developments necessary for the optimization of the methodology.

An increasing interest in the DDMRP field by the Academy is observed, resulting in simulations, studies and methodology analyses. The Polytechnic University of Valencia uses DDMRP for students' group work according to the problem-based learning method [17] and many theses in different countries analyse how the DDMRP works to improve the theoretical knowledge on DDMRP methodology and introduce it to local companies.

Some studies address the main advantages and limitations of the method. According to Cuadra [16], the DDMRP allows to increase sales by a high percentage, to achieve a service rate of $99 \%$, to limit the stock and to reduce the delivery time. Meinzel [21] uses a simulation to address the five steps of implementation of the method, examining the obtained benefits that result in $+13 \%$ of average service level, $-22 \%$ in average lead time and $-31 \%$ average cost of inventory. De Biasi [25] shows that the DDMRP method allows to improve the information flows within the supply chain and the performance of the warehouses.

Many scholars investigate the reasons leading companies to choose the DDMRP and implement it in the manufacturing environment. According to Perälä [23], the key data needed for the DDMRP implementation within the company must be organized following the next points: to identify the product or item that can benefit from DDMRP application; to place the decoupling points in the BOM of the product; to calculate the zones and buffer levels. Marin [18] considers the novelties introduced by DDMRP the reasons why it finds opposition from some companies' staff members, who do not accept to change their habits. On the other hand, various authors consider essential the development of DDMRP-based software to be integrated into an ERP, for incentivizing organizations to choose the DDMPR method and allowing easier management of the tool by local companies [16], [18], [20].

According to the DDMRP methodology [10], the choice of some variables (namely the positioning of the buffers, the lead time and variability factors, as well as the determination of the safety stock) is based on the experience of the staff who must select the values of the parameters within a certain range. This procedure introduces a subjectivity in the method implementation that should be overcome by analyzing a larger sample of companies using the DDMRP to identify the most suitable sectors of application and provide a set of best practices and mathematical tools supporting the decisionmaking process [20], [18]. Lee et al. [19] propose a new safety stock formula for the calculation of the parameter, enhancing existing guidelines for the DDMRP implementation. Velasco Acosta et al. [27] developed a DDMRP model simulated through a discrete event software to evaluate the applicability of the method in a complex manufacturing environment, considering a number of BOM levels up to 4 , finding that the customer satisfaction level can be improved by $41 \%$ and the average on-hand stock can be reduced by $18 \%$.

Few papers consider the relation of the DDMRP to Supply Chain Management (SCM), though the level of service and the reduction of delivery times can directly affect the customer's relationship with the company. Achergui [26] use the DDMPR buffer positioning approach applied to a hybrid MTO/MTS manufacturing system, demonstrating a viable reduction of the inventory costs for small supply chain networks. Santos [24] evaluates the impact that DDMRP has on the SCM processes, through the AHP (Analytic Hierarchy Process) multi-criteria decision support technique; the author finds that the three most impacted processes are production flow management, demand management and order fulfilment. Pekarcíková et al. [22] analyse the use of multiple product-related BOMs to indicate different levels in the supply chain considering the demand behaviour, with the aim of extending the DDMRP knowledge base in the context of Industry 4.0.

A list of the required future research developments apt to foster the adoption of the DDMRP method, according to the reviewed publications, is sketched in the figure 2 . In the circles, the number of papers referring to the required insight. 


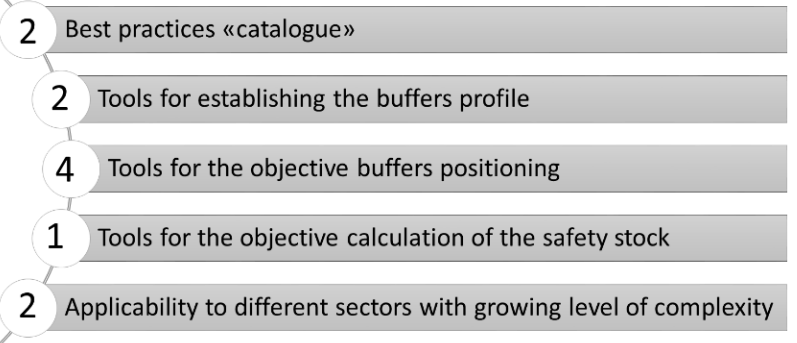

Fig. 2. Future developments of the studies on the DDMRP method, as expected by the papers included in the review.

\subsection{Group 2: Comparison with other methodologies}

The second group contains 8 publications, 6 papers and 2 theses, where DDMRP is compared with other methodologies, namely MRP and MRPII (Manufacturing Resources Planning), that it aims to overcome, the Economic Order Quantity (EOQ) tool and Kanban method.

Miclo et al. [31], [32], [33] use the discrete events simulation and the Kanban game ${ }^{1}$ data as input data to compare the DDMRP with MRPII, using as main indicators the On-Time Delivery (OTD) and Working Capital (WC). The results obtained show that DDMRP achieves better output indicators than MRPII with less WC and WIP, but with a less satisfactory OTD. Reference orders are much smaller in the case of the DDMRP, but more frequent than in the MRPII; however, the increase in the number of orders does not generate a correspondent increase in the number of setups for the machines, which was set by the execution priorities of the DDMRP. Moreover, the DDMRP method seems to be more stable when facing the variability of real demand, although during the simulation some products went out of stock. As expected, the DDMRP efficiently anticipates the peaks in demand orienting the management to the pull logic for the normal demand and the push logic for the peaks. Still using a discrete events simulation, Shofa et al. [29] compare the DDMRP with the MRP focusing on the inventory level under long lead time and uncertain demand scenarios, finding that using the DDMRP method the inventory level is more stable and the stock level is reduced by $11 \%$. Simulating the behaviour of four production planning and control systems (DDMRP, MRP, Kanban and Optimised Production Technology) applied to multi-stage assembly systems under different levels of bottleneck severity and delivery date tightness, Thurer et al. [34] found that DDMRP maintains a high level of performance also for severe bottleneck, with the lower inventory levels. Miclo et al. [12] simultaneously compare DDMRP with the MRPII and the Kanban systems at different levels of demand variability; they found that Kanban has a slightly lower WIP than DDMRP on average, while MRPII provides the worst results. According to the authors, the innovation of DDMRP lies in the fact that this methodology makes use of the best practices of the two previous approaches. The dynamic buffers have the function of absorbing the variability and allow the effective scheduling of the production, and a constant level of protection from the effect of nervousness. Finally, unlike the Kanban system, DDMRP uses buffers selectively, applying them only where they are needed. The comparison between DDMRP and EOQ, performed through a discrete event simulation in an ideal environment by Tounsi [28], shows how the DDMRP method uses less capital in stocks and WIP, with a higher percentage of orders fulfilled than the EOQ. Table 2 summarises the main advantages of the different methods as highlighted by the reviewed authors.

\begin{tabular}{|l|c|c|c|}
\hline Method & Advantages & Respect to & REF \\
\hline \multirow{4}{*}{ MRP } & OTD slightly better & DDMRP & {$[31][32][33]$} \\
\cline { 2 - 4 } & Fewer stock outages even if of larger quantities & DDMRP & {$[29]$} \\
\cline { 2 - 4 } & Less responsive to small lead time changes & DDMRP & {$[29]$} \\
\hline \multirow{5}{*}{ DDMRP } & Lower working capital & MRP, MRPII and EOQ & {$[31][32][33]$} \\
\cline { 2 - 4 } & Lower WIP & MRPII & {$[31][32][33]$} \\
\cline { 2 - 4 } & Stable responding to the variability of real demand & MRPII & {$[31][32][33]$} \\
\cline { 2 - 4 } & Inventory trend centred & MRPII & {$[31][32][33]$} \\
\cline { 2 - 4 } & Lower inventory level & MRPII & {$[31][32][33]$} \\
\cline { 2 - 4 } & Smaller and more frequent orders & MRPII & {$[32][33]$} \\
\cline { 2 - 4 } & E higher percentage of orders fulfilled & {$[28]$} \\
\cline { 2 - 4 } & Unfulfilled orders are fulfilled in a shorter time & EOQ & {$[29][34]$} \\
\cline { 2 - 4 } & Lower inventory level & MRP (KANBAN) & {$[28]$} \\
\cline { 2 - 4 } & Shorter delivery times & KANBAN & {$[12]$} \\
\hline KANBAN & Selective use of buffers & MRP and DDMRP & {$[12]$} \\
\hline
\end{tabular}

Table 2. Comparison of the different methodologies for managing inventory planning.

\footnotetext{
${ }^{1}$ http://www.cipe.fr/jeux-et-seminaires/jeu-du-kanban
} 


\subsection{Group 3: Case studies}

The third group collects 17 case studies retrieved from the literature of which 13 theses and 5 research articles, which describe 15 simulations on real data and only 2 cases reporting the method implementation in companies; the case studies explore the benefits and difficulties faced by the manufacturing industry. Table 3 lists the case studies and the company context and motivations for adopting or simulating the DDMRP.

\begin{tabular}{|c|c|c|}
\hline $\begin{array}{c}\text { Case study: company name / } \\
\text { sector }\end{array}$ & Company context / needs / issues to overcome & REF. \\
\hline $\begin{array}{l}\text { COASA / oils and lubricants for } \\
\text { the aviation industry }\end{array}$ & $\begin{array}{l}\text { Obsolescence of the products ( } 90 \%) \text {; Excessive stock; Unnecessary products } \\
\text { purchase due to unplanned events }\end{array}$ & [35] \\
\hline $\begin{array}{l}\text { GSA / kitchen tools and small } \\
\text { appliances }\end{array}$ & $\begin{array}{l}\text { Need to improve the service level and reduce the costs to recover market } \\
\text { segments }\end{array}$ & {$[36]$} \\
\hline $\begin{array}{l}\text { Consumer-Packaged Goods (Food } \\
\text { sector) }\end{array}$ & $\begin{array}{l}\text { Perishable goods and high inventory turns (1.6 to } 2.5 \text { weeks); simulating } \\
\text { planning under uncertainty at finite capacity }\end{array}$ & [37] \\
\hline White goods & $\begin{array}{l}\text { Need to improve the service level and reduce the costs to recover market } \\
\text { segments }\end{array}$ & [38] \\
\hline Wa-Armonia / cosmetics & Need to improve the service level and reduce the inventory costs & [39] \\
\hline $\begin{array}{l}\text { Automotive Lighting / Outdoor } \\
\text { lighting for automotive }\end{array}$ & $\begin{array}{l}\text { Variable and unpredictable demand, due to the change in consumers' behaviour; } \\
\text { growing structural complexity of the supply chain; architectural complexity of } \\
\text { the products. }\end{array}$ & [40] \\
\hline ISEO locks / locking systems & $\begin{array}{l}\text { Need for higher flexibility and reduced delivery time, confirming the service } \\
\text { level }\end{array}$ & [41] \\
\hline $\begin{array}{l}\text { Exquise1928 / soft drinks and } \\
\text { syrups }\end{array}$ & Interest in improving the company's PCS & [42] \\
\hline $\begin{array}{l}\text { Dayco Ivrea / components for the } \\
\text { automotive sector }\end{array}$ & $\begin{array}{l}\text { Management of raw material stock not effective, causing failures in production } \\
\text { planning; suppliers lead time and demand variability. }\end{array}$ & [43] \\
\hline $\begin{array}{l}\text { Science4you / scientific and } \\
\text { educational games/tools }\end{array}$ & $\begin{array}{l}\text { Market seasonality; high variability of the demand. Failures in raw materials } \\
\text { stock management; long lead times. }\end{array}$ & [44] \\
\hline Food & Excessive stock; obsolescence of the products. & [45] \\
\hline Automotive & Need to improve inventory level management. & [30] \\
\hline Food-sauces & High fluctuations in the product demand; unstable inventory level. & [46] \\
\hline AeroCo / Aircraft components & Interest in analysing the applicability of the DDMRP. & [47] \\
\hline $\begin{array}{l}\text { Companies CS1 (padlocks), CS2 } \\
\text { (components for household } \\
\text { appliances), CS3 (special parts for } \\
\text { the automotive industry) }\end{array}$ & $\begin{array}{l}\text { CS1: considerable purchase lead times; only one experienced responsible for } \\
\text { purchase orders. Need to adjust the inventory level to the market requirements, } \\
\text { whilst maintaining the service level. } \\
\text { CS2: complex supply chain; high levels of raw material at a significant cost; } \\
\text { final products stored in the company warehouse before delivery to customers; } \\
\text { demand and supply variability and lack of visibility; stock outs and rush orders. } \\
\text { CS3: three production plants; complex supply chain, as well as purchasing and } \\
\text { production planning. }\end{array}$ & [48] \\
\hline Company CS1 & (CS1 as above) & $\begin{array}{l}{[49]} \\
{[50]}\end{array}$ \\
\hline
\end{tabular}

Table 3. Case studies included in the review.

As can be seen in the table 3, the application of the DDMRP methodology to the industrial environment is mainly studied to demonstrate its efficacy in responding to demand and lead time variability, improving inventory management, with a resulting economic advantage, and service level. Some criticalities are also revealed.

The simulation performed by Castro J.E.N. [35], starting from an ABC classification of Coasa's products (oils and lubricants for the aviation industry), finds that excess stocks and expired products have been eliminated, reducing the stock by $25 \%$ and estimating an economic return of about $\$ 10,000$ per year. A reduction in available stocks, with a simultaneous increase in the ADU and the reduction in stock coverage, is observed also by Kortabarria [48] in the companies where the DDMRP method was implemented. Salazar \& Arenas [38] highlight a decrease in total inventories up to $60 \%$ with an increase in sales up to $20 \%$, reducing the reactivity time to the market demand up to $80 \%$, in the white goods company they analysed. Brahimi \& Saadi [42] compare the planning system of a company bottling and selling soft drinks with and without DDMRP; they note that the DDMRP model improves the stock coverage and makes the inventory level more stable, while it lowers the inventory turnover rate. Leguizamo \& Totaitive [32] in simulating a single product, talc, find that the conversion to the DDMRP methodology guarantees a reduction in costs. Dimas et al. [46] show how the DDMRP lower the inventory levels of a company producing food sauce allowing a savings of 53.5\%.

According to Ptak and Smith [10], the reduction of stocks corresponds to an unchanged or even better level of service. Salazar \& Arenas [38] find a level of service above 99\%, while Provenzano [40], in his simulation on a group of finished products (Automotive Lighting), finds that using the DDMRP the customer demand is satisfied without corrective actions. Kortabarria et al. [49], [50] also stress that the reduction in stocks is not followed by a worsening of the level of service. 
A reduction of the delivery times is observed by Abith Zachariah [41], together with a higher level of service and satisfaction for the customers in a company producing locking systems. Shofa et al. [30], through a simulation using the data of an automotive company, claim that DDMRP allows a reduction in delivery times and lead time (- 94\%), improving the service level. Ducrot \& Ahmed [37] simulate a European perishable food production company and compare conventional APS software and DDMRP planning, observing the service level and the inventory turns; according to their calculations, DDMRP performs better than the heuristics-based planning in three scenarios out of four and it provides similar results as an advanced mathematical solver. A service level approaching $98 \%$ (10\% increase over the current service level) is obtained for one production line of the GSA company by Builes Henao through a discrete event simulation [36]. Perez Castro [45] argues that thanks to the implementation of DDMRP in a food company, the ROA improves by 2 to $3 \%$ and the products remain less time in stock.

Applying the DDMRP methodology to a company selling components for the automotive sector Hincapiè [43] shows that it makes planning management easier since managers can observe the status of stocks on a daily basis, prioritize critical orders and keep the stock in the desired range. According to Kortabarria [48], the implementation of DDMRP entails a fundamental change in the material planning process in each of the three companies (CS1, CS2, and CS3) he analysed after the migration from MRP to DDMRP. In all these companies, day-to-day planning was previously considered not practicable, as the information gathering process was time-consuming and not easy. After the implementation of the DDMRP method, the flow of information along the entire supply chain has significantly improved, and the three companies acquired access to the inventory daily, thus being able to plan in a simple and agile way the needs of materials and to manage the status of supplies, obtaining greater flexibility, saturation and synchronization of the production lines as well as the absence of urgent orders. Both the production and procurement planning should be adapted to the DDMRP implementation: for example, within the ISEO group, the ADU must be evaluated on a weekly instead of monthly basis as carried out previously; the sizing parameters must be continuously updated to dynamically adjust and optimize stock levels; when a new supplier is involved the related information must be promptly updated due to the dynamic nature of the size of the buffers [41].

The alerts dictated by the method, and the priority they represent for the decision-making process, allow to prevent critical situations of shortages or excess stocks, as pointed out by Tavares [44] in her simulation of a toys company; however, the author observes that the DDMRP methodology it is not intuitive to apply and requires preparatory steps as well as many input data. Moreover, the definition of the associated decision-making criteria depends on the practitioners' experience and the level of accuracy in defining the DDMPR parameters can impact the method applicability. So, the implementation of the DDMRP requires staff to be trained on the principles and operation of the method, an aspect that is not trivial since generally in the companies the orders and production planning is entrusted to staff members with extensive professional experience in this regard [40]. Abith Zachariah analyses the costs for the implementation of the new methodology within the ISEO group, quantifying the costs for the theoretical and practical training of the employees, as well as the costs for upgrading the used management software to support the planning and operational execution of the new method, finding that the overall expenditure is around 40-50 $\mathrm{k}$ [41].

Other criticalities of the DDMRP are emphasized in the reviewed case studies: the efficiency of DDMRP seems to be affected by the presence of long lead times in the intermediate levels of the supply chain [40], so it cannot be applied to all buffers [41]; moreover, the method is sensitive to the value of the decoupled delivery time and the orders' frequency and variability, which should not be empirically assigned [36]. Moreover, it is observed that the DMRP cannot be applied to all products or activities [22]: the purchase of raw materials become critical when delivery times are too long and cannot be related to the effective demand for long time ranges.

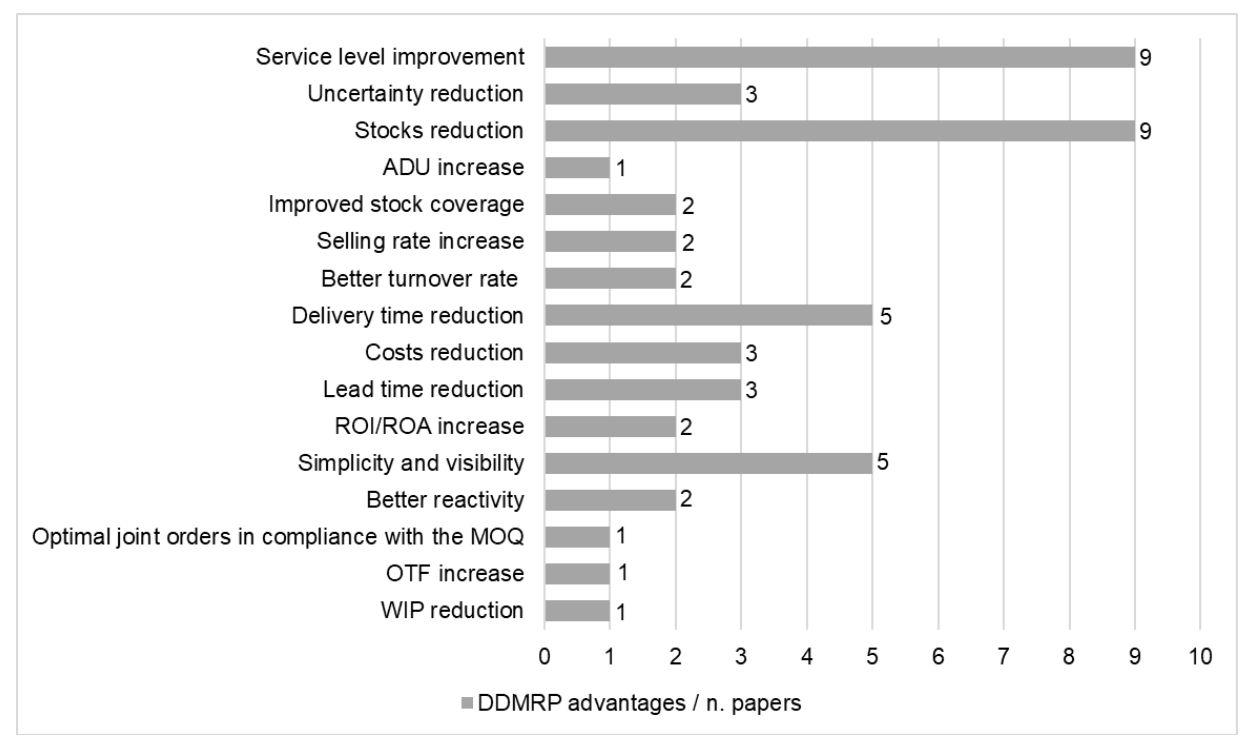

Fig. 3. DDMRP advantages as retrieved from the reviewed case studies. 
The DDMRP supply logic does not apply if the quantity and not the price is negotiated, since if the price is low the company will buy more material than the actual requirement because the cost of keeping it in stock is lower than the higher prices the company would pay in the subsequent purchase period [41]. Figures 3 and 4 summarize the advantages and disadvantages of the DDMRP method as retrieved from the reviewed case studies. The bars represent the number of papers citing the considered advantage/disadvantage.

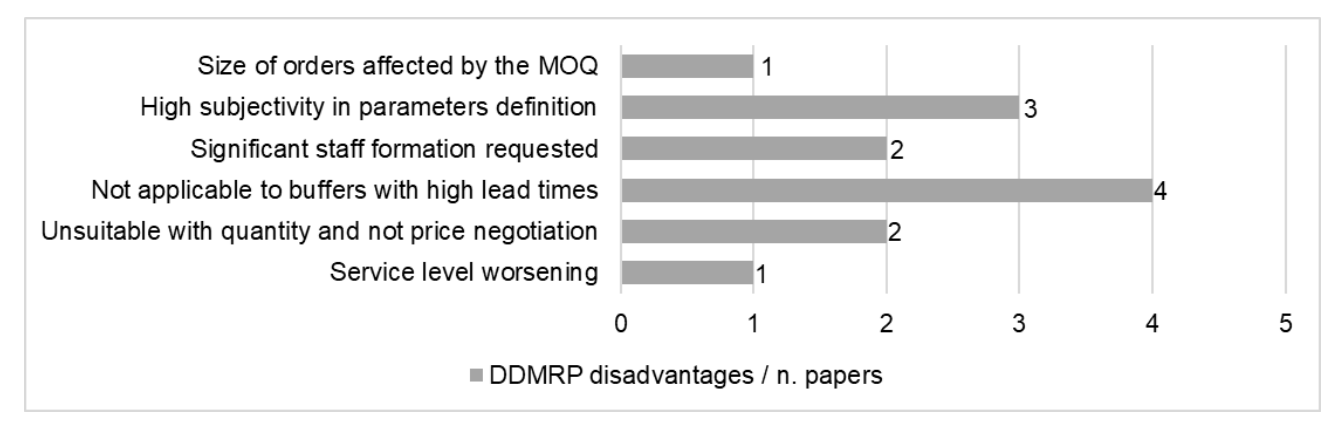

Fig. 4. DDMRP disadvantages as retrieved from the reviewed case studies.

\section{Conclusion}

The presented review of the available academic studies on the DDMRP methodology highlights the current academic research trends. The main efforts of the scholars are directed to the study of the basic principles of the method, often comparing it to the more established methods. Simulations are widely used to validate the original method and confirm some of the claimed advantages of the DDMRP, while since most of the organizations present complex scenarios the greatest challenge of the simulations is the setting of the parameters for the implementation of the DDMRP, still empirically based and poorly documented. Among these, the enormous subjectivity that dominates the positioning of the buffers is identified as particularly critical and this is still one of the gaps affecting the research papers on the application of this methodology and the implementation in the organizations as well, where a qualified and properly trained specialist should be dedicated to the activities of regularly monitor the demand and consequently adapt the production buffers.

A growing interest in the implementation of the DDMRP in the real industrial environment is proved by the number of case studies, mainly presented in Master or $\mathrm{PhD}$ theses after the candidates' internship in local companies; however, most of the retrieved case studies are simulations based on real data and only a few empirical ones. The analyses show that the method allows improving the organisations' production control system overcoming some of the identified weak points, while the costs of its implementation should be taken into account. However, the application of the method to the industrial context is limited to the analysis of the problems of a single company, often considering the possible transition from an MRP system to DDMRP. Moreover, the exiguity of studies reporting the real implementation of the method in the industrial context limits the possibility of compiling a catalogue of best practices.

From this study emerged that two main future research lines can improve the knowledge on the DDMRP applicability and effectiveness into the industrial environment: the development of tools and objective methodologies for the parameters set and the positioning of the buffers and the systematic analysis of the applicability of the method in relation to the sector and the complexity of the organization and its supply chain.

\section{References}

[1] Bagni, G.; Godinho Filho, M.; Thürer, M. \& Stevenson, M. (2021). Systematic review and discussion of production control systems that emerged between 1999 and 2018. Prod. Plan. Control, Vol. 32, pp 511-525, ISSN: 0953-7287

[2] Katuu, S. (2020). Enterprise Resource Planning: Past, Present, and Future. New Rev. Inf. Netw., Vol. 25(1), pp 3746, ISSN: 17407869.

[3] Dolgui, A. \& Prodhon, C. (2007). Supply planning under uncertainties in MRP environments: A state of the art. Annu. Rev. Control., Vol. 31 (2), pp 269-279, ISSN: 13675788.

[4] Li, Q. \& Disney, S.M. (2017). Revisiting rescheduling: MRP nervousness and the bullwhip effect. Int. J. Prod. Res., Vol. 55(7), pp 1992-2012, ISSN: 1366588X.

[5] Wang, X. \& Disney, S.M. (2016). The bullwhip effect: Progress, trends and directions. Eur. J. Oper. Res., Vol. 250 (3), pp 691-701. ISSN: 03772217.

[6] Bregni, A.; D’Avino, M. \& Schiraldi, M.M. (2011). A new approach to lower MRP nervousness. Ann. DAAAM Proc. Int. DAAAM Symp., 2011, Vienna (Austria), ISSN: 17269679, ISBN: 9783901509834, Katalinic B. (Ed.): pp. 1513-1514, DAAAM International, Vienna.

[7] Rossi, T.; Pozzi, R.; Pero, M. \& Cigolini, R. (2017). Improving production planning through finite-capacity MRP. Int. J. Prod. Res., Vol.55 (2), pp 377-391, ISSN: 1366588X.

[8] Thevenin, S.; Adulyasak, Y. \& Cordeau, J.F. (2021). Material Requirements Planning Under Demand Uncertainty Using Stochastic Optimization. Prod. Oper. Manag., Vol. 30 (2), pp 475-493. ISSN: 19375956. 
[9] Ptak, C. \& Smith, C. (2011). Orlicky's Material Requirements Planning (third ed.), McGraw Hill Professional, ISBN: $0071755632,9780071755634$.

[10] Ptak, C. \& Smith, C. (2016). Demand Driven Material Requirements Planning (DDMRP). Industrial Press Incorporated, ISBN: $9780831193850,0831193859$.

[11] El Marzougui, M.; Messaoudi, N.; Dachry, W.; Sarir, H. \& Bensassi, B. (2020). Demand Driven MRP: Literature review and research issues, Proceedings of the 13ème Conf. Int. Model. Optim. Simul., (MOSIM2020), 2020, AGADIR (virtual), Morocco. hal-03193163.

[12] Miclo, R.; Lauras, M.; Fontanili, F.; Lamothe, J. \& Melnyk, S.A. (2019). Demand Driven MRP: assessment of a new approach to materials management. Int. J. Prod. Res., Vol. 57 (1), pp 166-181. ISSN: 1366588X.

[13] Orue, A.; Lizarralde, A. \& Kortabarria, A. (2020). Demand driven MRP - the need to standardise an implementation process. Int. J. Prod. Manag. Eng., Vol. 8 (2), pp 65-73. ISSN: 23404876.

[14] Azzamouri, A.; Baptiste, P.; Dessevre, G. \& Pellerin, R. (2021). Demand Driven Material Requirements Planning (DDMRP): A systematic review and classification. J. Ind. Eng. Manag., Vol 14 (3), pp 439-456. ISSN: $2013-0953$.

[15] Miclo, R.; Fontanili, F.; Lauras, M.; Lamothe, J. \& Milian, B. (2016). An empirical study of Demand-Driven MRP, Proceedings of the 6th International Conference on Information Systems Logistics and Supply Chain - ILS 2016, June 1-4, 2016, Bordeaux (France), pp 1-7.

[16] Cuadra, R.R. (2017) Estudio Del Ddmrp (Demand Driven Materials Requirement Planning), Master Thesis, Escuela de Ingenieria Industriales, University of Valladolid, Valladolid, Spain.

[17] Kortabarria, A. \& Elizburu, A. (2018). Implementing Management Systems and Demand Driven MRP concepts: A Project Based Learning experience in Industrial Organization Engineering, Proceedings of the 4th International Conference on Higher Education Advances (HEAd'18), 2018, Universitat Politecnica de Valencia, Valencia (Spain), pp 543-551. doi:10.4995/head18.2018.8033.

[18] Marin, A. (2018). DDMRP: un approccio ibrido tra metodi push (MRP) e metodi pull (Lean), Mater Thesis, Corso di Laurea in Economia e Gestione delle Aziende, University Ca' Foscari, Venezia, Italy.

[19] Lee, C.J. \& Rim, S.C. (2019) A Mathematical Safety Stock Model for DDMRP Inventory Replenishment, Math. Probl. Eng., Vol. 2019, Article ID 6496309. ISSN: 15635147.

[20] Bahu, B., Bironneau, L. \& Hovelaque, V. (2019). Compréhension du DDMRP et de son adoption: premiers éléments empiriques. Logistique Manag., Vol. 27 (1), pp 20-32. ISSN: 1250-7970.

[21] Meinzel L. (2019). DDMRP: presentation of a new solution of stock management and master production scheduling, Master Thesis, Escola Tècnica Superior d'Enginyeria Industrial de Barcelona, Universitat Politecnica de Catalunya, Barcelona, Spain.

[22] Pekarcíková, M.; Trebuna, P.; Kliment, M. \& Trojan, J. (2019). Demand driven material requirements planning. some methodical and practical comments. Manag. Prod. Eng. Rev., Vol. 10 (2), pp 50-59. ISSN: 20821344.

[23] Perälä, J. (2020). Demand Driven Material Requirement Planning Suitable components and data considerations, Master Thesis, School of Technology, University of Applied Sciences, Vaasa, Finland.

[24] Alves da Silva Santos, L. (2020). Demand-Driven Material Requirements Planning (DDMRP) Implementation Impacts on Supply Chain Management Strategic Processes: an AHP Approach, Master Thesis, Sao Carlos School of Engineering, University of Sao Paulo, Brazil.

[25] Gavaz De Biasi, F. (2020). Pianificazione della Produzione Secondo l'Approccio DDMRP. Un'Analisi Teorica. Master Thesis, Dipartimento di Tecnica e Gestione dei Sistemi Industriali, University of Padova, Padova, Italy.

[26] Achergui, A.; Allaoui, H. \& Hsu, T. (2020). Strategic DDMRP's Buffer Positioning for hybrid MTO/MTS manufacturing. Proceedings of the 2020 IEEE Int. Conf. Technol. Manag. Oper. Decis. (ICTMOD), IEEE, pp. 1-8. doi:10.1109/ICTMOD49425.2020.9380588.

[27] Velasco Acosta, A.P.; Mascle, C. \& Baptiste, P. (2020). Applicability of Demand-Driven MRP in a complex manufacturing environment. Intern. Journal of Prod. Research, Vol. 58 (14), pp 4233-4245. DOI: 10.1080/00207543.2019.1650978.

[28] Tounsi, W. (2018). Comparaison des approches DDMRP et EOQ: modélisation et simulation d'un cas d'étude, Master Thesis, Ecole Polytechnique de Montreal, Université de Montreal, Montreal, Canada.

[29] Shofa, M.J.; Moeis, A.O. \& Restiana, N. (2018). Effective production planning for purchased part under long lead time and uncertain demand: MRP Vs demand-driven MRP. IOP Conf. Ser. Mater. Sci. Eng., Vol. 337, 012055. ISSN: 1757899X.

[30] Shofa, M.J. \& Widyarto, W.O. (2017). Effective production control in an automotive industry: MRP vs. demanddriven MRP. AIP Conf. Proc. 1855, 020004. ISSN: 15517616.

[31] Miclo, R. (2016) Challenging the" Demand Driven MRP” Promises: a Discrete Event Simulation Approach, PhD Dissertation, Centre Génie Industriel, Ecole des Mines d'Albi-Carmaux, Albi, France.

[32] Miclo, R.; Fontanili, F.; Lauras, M.; Lamothe, J. \& Milian, B. (2016). MRP vs. Demand-driven MRP: Towards an objective comparison. Proceedings of the 2015 Int. Conf. Ind. Eng. Syst. Manag. IEEE IESM 2015, pp: 1072-1080. doi:10.1109/IESM.2015.7380288.

[33] Miclo, R.; Fontanili, F.; Lauras, M.; Lamothe, J. \& Milian, B. (2016). An empirical comparison of MRPII and Demand-Driven MRP, IFAC-PapersOnLine, Vol. 49 (12), pp 1725-1730. ISSN: 24058963. 
[34] Thürer, M.; Fernandes, N.O. \& Stevenson, M. (2020). Production planning and control in multi-stage assembly systems: an assessment of Kanban, MRP, OPT (DBR) and DDMRP by simulation, International Journal of Production Research, 1-15. DOI: 10.1080/00207543.2020.1849847.

[35] Castro, J.E.N. (2019). Diseño De Un Modelo De Gestión Demand Driven - Mrp, Para El Aprovisionamiento De Productos Aceites Y Lubricantes Aéreos Para Una Flota De Aviones Supersónicos, Master Thesis, Facultad De Ciencias Naturales Y Matemáticas Departamento De Matemáticas, Escuela Superior Politécnica del Litoral, Guayaquil, Ecuador.

[36] Builes Henao, J.L. (2019). Marco De Referencia Para La Implementacion De Ddmrp En La Planta De Non Stick Gsa, Master Thesis, Escuela de Ingenieria, Universidad EAFIT, Medellin, Colombia.

[37] Ducrot, L. \& Ahmed, E. (2019). Investigation of potential added value of DDMRP in planning under uncertainty at finite capacity, Thesis, Master of Applied Science in Supply Chain Management, Massachusetts Institute of Technology, Cambridge (MA), USA.

[38] Salazar, M. \& Arenas J. (2019). Disminución de niveles de inventario de repuestos de productos de línea blanca, basados en la metodología DDMRP, Thesis, Faculdad de Ingenieria, Universidad de Antioquia, Medellin, Colombia.

[39] Linares Leguizamo, M.D. \& Totaitive M. (2017). Diseño del modelo DDMRP para la planeación de la Producción en la empresa Wa-Armonía, Thesis, Faculdad de Ingenieria, Pontificia Universidad Javeriana, Bogotà, Colombia.

[40] Provenzano, F. (2020). Modelli innovativi di gestione delle scorte nella filiera logistica: applicazione del metodo DDMRP nel settore automotive, Master Thesis, Collegio di Ingegneria Gestionale, Politecnico di Torino, Italy.

[41] Abith Zachariah, G. (2018). Demand Driven Materials Requirement Planning (DDMRP) A new method for production and planning management, Master Thesis, Management, Economics and Industrial Engineering, Politecnico di Milano, Milano, Italy.

[42] Brahimi, B. \& Saadi, M.A. (2019). Amélioration de la planification de la production de la chaine logistique par l'application de la méthode DDMRP, Master Thesis, Faculté de TECHNOLOGIE, Université Aboubakr Belkaïd, Tlemcen, Algeria.

[43] Hincapiè, V.V. (2018). Application of Demand Driven Material Requirement Planning (DDMRP) methodology for components inventory management in a company of automotive industry, Master Thesis, Engineering and Management, Politecnico di Torino, Torino, Italy.

[44] Tavares, A.C.M. (2019). Demand Driven Material Requirements Planning (DDMRP): Estudo Exploratório, Master Thesis, Faculdade de Ciencias e Tecnologia, Universidade Nova de Lisboa, Lisboa, Portugal.

[45] Perez Castro, M.G. (2018). Diseño De Un Modelo De Gestión Demand Driven - MRP, Para el Proceso de Compras de Materias Primas de una Empresa de Insumos Alimenticios, Master Thesis, Facultad De Ciencias Naturales Y Matemáticas Departamento De Matemáticas, Escuela Superior Politécnica del Litoral, Guayaquil, Ecuador.

[46] Dimas Mukhlis, H.F.; Indraefrialdi, J. \& Rimawan, E. (2019). Inventory Management using Demand Driven Material Requirement Planning for Analysis Food Industry. Int. J. Innov. Sci. Res. Technol., Vol. 4 (7), pp $495-499$. ISSN:-2456-2165.

[47] Johansson, R. \& Sodermark, G. (2019). Understanding the Requirements of Forecast in Demand Driven Material Requirements Planning, Master Thesis, Department of Technology Management and Economics Division of Supply and Operations Management, Chalmers University of Technology, Gothenburg, Sweden.

[48] Kortabarria Igartua, A. (2018). Analysis of the performance of Demand Driven Material Requirements Planning on supply chain management: A multiple case study, PhD Dissertation, Mechanical and Manufacturing Department, Mondragon Unibertsitatea, Bilbao, Spain.

[49] Kortabarria, A.; Apaolaza, U.; Lizarralde, A. \& Amorrortu, I. (2018). Material management without forecasting: From MRP to demand driven MRP, J. Ind. Eng. Manag., Vol. 11 (4), pp 632-650. ISSN: 20130953.

[50] Kortabarria, A.; Apaolaza, U. \& Lizarralde, A. (2019). Demand Driven MRP - Nuevo método para la gestión de la Cadena de Suministro: Un estudio de caso, Dir. y Organ., Vol. 67, pp 22-29. ISSN: 21716323. 